\title{
Greenhouse gas emissions from waste management-assessment of quantification methods
}

Article

Accepted Version

Mohareb, E. A., MacLean, H. L. and Kennedy, C. A. (2011) Greenhouse gas emissions from waste managementassessment of quantification methods. Journal of the Air \& Waste Management Association, 61 (5). pp. 480-493. ISSN 1096-2247 doi: https://doi.org/10.3155/1047-3289.61.5.480 Available at https://centaur.reading.ac.uk/44988/

It is advisable to refer to the publisher's version if you intend to cite from the work. See Guidance on citing.

Published version at: http://dx.doi.org/10.3155/1047-3289.61.5.480

To link to this article DOI: http://dx.doi.org/10.3155/1047-3289.61.5.480

Publisher: Taylor \& Francis

All outputs in CentAUR are protected by Intellectual Property Rights law, including copyright law. Copyright and IPR is retained by the creators or other copyright holders. Terms and conditions for use of this material are defined in the End User Agreement.

www.reading.ac.uk/centaur 
Central Archive at the University of Reading

Reading's research outputs online 


\title{
Greenhouse Gas Emissions from Waste Management - Assessment of Quantification Methods
}

\author{
Mohareb EA, University of Toronto, Toronto, ON, Canada \\ MacLean HL, University of Toronto, Toronto, ON, Canada \\ Kennedy CA, University of Toronto, Toronto, ON, Canada
}

\begin{abstract}
Of the many sources of urban greenhouse gas (GHG) emissions, solid waste is the only one for which management decisions are undertaken primarily by municipal governments themselves and is hence often the largest component of cities' corporate inventories. It is essential that decision makers select an appropriate quantification methodology and have an appreciation of methodological strengths and shortcomings.
\end{abstract}

This work compares four different waste emissions quantification methods including Intergovernmental Panel on Climate Change (IPCC) 1996 guidelines, IPCC 2006 guidelines, United States Environmental Protection Agency Waste Reduction Model (USEPA WARM) and the Federation of Canadian Municipalities Partners for Climate Protection (FCM-PCP) quantification tool. Waste disposal data for the Greater Toronto Area (GTA) in 2005 are used for all methodologies; treatment options, including landfill, incineration, compost, and anaerobic digestion, are examined where available in methodologies.

Landfill was shown to be the greatest source of GHG emissions, contributing more than $3 / 4$ of total emissions associated with waste management. Results from the different landfill gas quantification approaches ranged from an emissions source of $557 \mathrm{kt} \mathrm{CO}_{2} \mathrm{e}(\mathrm{FCM}-\mathrm{PCP})$ to a carbon sink of $-53 \mathrm{kt}$ $\mathrm{CO}_{2} \mathrm{e}$ (USEPA WARM). Similar values were obtained between IPCC approaches. The IPCC 2006 method was found to be more appropriate for inventorying applications as it uses a waste-in-place (WIP) approach, rather than a methane commitment (MC) approach, despite perceived onerous data requirements for WIP.

MC approaches were found to be useful from a planning standpoint; however, uncertainty associated with their projections of future parameter values limits their applicability for GHG inventorying. MC and WIP methods provided similar results in this case study; however, this is casespecific, due to similarity in assumptions of present and future landfill parameters and quantities of annual waste deposited in recent years being relatively consistent. 


\section{Implications}

This paper provides insight for municipalities, consultants, and others involved in greenhouse gas quantification from waste management with regard to emissions from various treatment options and variation due to methodological selection. By examining the differences in emissions from the quantification tools and guidelines examined in this research, these professionals will gain insight on where shortcomings and methodological differences exist and how these may be addressed. It also provides an illustration of how theoretical yield gas calculations can be similar in magnitude to those calculated using a waste-in-place approach.

\section{Acknowledgements}

The authors would like to thank the people of Canada, who funded this work through the Natural Sciences and Engineering Research Council (NSERC), Adrian Mohareb \& Julian Cleary for their assistance, and Prof. Danny Harvey \& three anonymous reviewers of this work for their very helpful comments. Additionally, the authors are appreciative of all assistance provided by the GTA regional municipalities, especially Trevor Barton (Peel Region), Laura Darnell-Omotani (York Region), Irene Ford \& Brian Van Opstal (City of Toronto) and Walter Scattolon \& John Watson (Halton Region). 


\section{INTRODUCTION}

The release of landfill gas (LFG) resulting from anaerobic decomposition of municipal solid waste (MSW) is generally quantified in greenhouse gas (GHG) emissions inventories conducted by cities. For 2007, this emissions source represented $21 \mathrm{Mt}$ (roughly 3\%) of total emissions tabulated in the Canadian national GHG inventory and $127 \mathrm{Mt}(2 \%)$ in the US inventory ${ }^{1,2}$. Municipalities, who have been strong jurisdictional champions in addressing climate change, play the principal role in managing these GHGs since their decisions dictate diversion, treatment and mitigation (such as LFG capture) practices. The opportunity for reductions is large; an example from the 2004 City of Toronto inventory suggests solid waste contributed $3 \%$ of community-wide emissions, however its proportion of corporate emissions (those stemming strictly from municipal government activities) was $45 \%{ }^{3}$. Additionally, waste emissions generally contribute a larger proportion of community-wide municipal emissions in the developing world (e.g. up to $40 \%$ in Rio De Janeiro ${ }^{4}$ ). The method selected for quantifying waste-related emissions is important, as projects to mitigate MSW-related GHG emissions are likely to be a high priority; Kennedy et al demonstrated that waste emissions reduction strategies tend to be the most cost-effective of municipal projects targeting GHGs regardless of region, underscoring the importance of proper quantification for planning purposes 5 .

Greenhouse gas emissions are released through a number of waste management treatment options. However, the greatest source of waste-related GHGs in the 2007 Canadian National Inventory is anaerobic digestion (AD) in landfills, contributing $95 \%$ of all Waste sector emissions ${ }^{1}$. When biogenic carbon is deposited in landfills, degradation processes become anaerobic after oxygen is depleted in the fill material, producing LFG that is roughly $50 \%$ methane $\left(\mathrm{CH}_{4}\right)$. This GHG is 25 times more potent over a 100-year timeframe than if the same biogenic carbon were aerobically degraded to $\mathrm{CO}_{2}$, which would presumably be a carbon-neutral process ${ }^{6}$. Hence, whenever landfill $\mathrm{CH}_{4}$ is oxidized through combustion or a specially-engineered landfill cover, a reduction in radiative forcing is achieved (compared to a case where $\mathrm{CH}_{4}$ emissions are not controlled). Other possible GHG sources from solid waste include ${ }^{7}$ :

1. Combustion of fossil-derived carbon in incineration systems resulting in the release of $\mathrm{CO}_{2}$

2. Production of $\mathrm{CH}_{4}$ from anaerobic conditions within composting operations

3. Release of $\mathrm{N}_{2} \mathrm{O}$ during nitrification in compost piles

4. Leakage of $\mathrm{CH}_{4}$ from anaerobic digestion reactors

5. Collection and transportation of waste to transfer \& treatment sites (indirect). 
While policy measures to reduce GHG emissions from MSW appear straightforward (such as improved recycling of wood products and diversion of food wastes), inaccurate quantification of these may distort the issue's scale (and economic feasibility, if carbon pricing is part of the rationale for a mitigation project). Comparison of emissions totals is complicated due to the fact that two different temporal boundaries have been applied to MSW emissions studies; GHGs can be quantified using either the methane commitment (MC; or Theoretical Yield Gas) method or the waste-in-place (WIP) method. The MC method requires the forecast of any future methane emissions associated with MSW deposited in the inventory year, basing this estimation on a projection of future landfill operation practices. The WIP method attempts to quantify methane released within the inventory year from all MSW waste previously deposited in landfills.

The objective of this paper is to quantify and compare GHG emissions associated with waste management using various methodologies that are currently employed in inventorying activities for waste, as different approaches are being used by cities globally (generally using MC approaches including USEPA WARM and IPCC 1996) ${ }^{4}$. The importance of this exercise stems from the potential for comparisons between global cities' emissions, which are likely to be made even though boundaries used in their inventories may differ. Quantification of a single case study provides insight into the effect of inconsistent methodological selection between these cities. Additionally, comparing different methodologies to quantify GHG emissions from MSW and analysis of the effects of parameter selection is useful for waste planners/managers. WIP and MC approaches are examined, looking at both direct and indirect emissions associated with different MSW management practices. Once the details of the nuances of quantification methodologies are clearer, policy makers will be able to select the approach that best suits their needs in a particular application (i.e. inventorying vs. waste management planning) and apply it with knowledge of its strengths and weaknesses.

Landfill, incineration, AD and/or composting GHG emissions are calculated, using the Greater Toronto Area (GTA) as a case study, by applying four commonly-used models: Intergovernmental Panel on Climate Change (IPCC) 1996, IPCC 2006, USEPA Waste Reduction Model (WARM) and the Federation of Canadian Municipalities - Partners for Climate Protection (FCM-PCP) quantification tool for communities ${ }^{7,8,9,10}$. Additionally, two modifications of the IPCC 2006 model are made to allow for further analysis; one to provide a MC calculation (henceforth termed IPCC $2006 \mathrm{MC}$ ) and one to provide a limited life cycle-based inventory (IPCC 2006 LC). The IPCC 2006 LC predominantly includes emissions/credits that would not be included in the IPCC 2006 MC, but that occur within the 
municipal boundary and may be relevant to a municipal emissions inventory. This results in a comparison of six different approaches.

\section{BACKGROUND}

Some information must be provided on the methodologies used in this study to provide an understanding of where they originated, how they are designed and their intended uses. In 1991, the IPCC initiated the National Greenhouse Gas Inventories Programme to commence work on methodologies for quantifying GHG dynamics for member countries ${ }^{8}$. The program aimed to attain consensus with its members by developing emissions/sink inventories and established a task force to aid nations in the quantification of their GHG emissions ${ }^{11}$. The result has been two guidelines (henceforth referred to as IPCC 1996 and IPCC 2006) which have two important differences; The IPCC 1996 model uses a MC calculation while the IPCC 2006 revision uses a WIP method (using > 10 years of detailed landfill disposal data).

The other main difference between the two models is the data requirement. As the 1996 method uses the MC approach, it is based on a simple calculation which employs an estimate of waste carbon content that is dissimilated to methane over an infinite time period (assuming no changes in landfill conditions). Only the tonnage deposited within the year of inventory is required, while default data can be applied to fill in any missing information. The IPCC 2006 WIP method requires the use of a more complex first-order decay model that estimates the degree of decomposition of accumulated carbon in landfilled waste based on half-life data of materials under given landfill conditions, which has a greater data requirement (waste deposited from 50 years prior is suggested).

Partners for Climate Protection (PCP), the Federation of Canadian Municipalities program on climate change action (in association with ICLEI's global Cities for Climate Protection program), has developed a spreadsheet tool that can be used by municipalities to complete a community and corporate GHG inventory ${ }^{10}$. This tool employs a MC approach, as it simply requires an estimate of waste landfilled in a given year, based on a fixed emissions factor $\left.\left(\mathrm{t}_{2} \mathrm{e} \text { ( } \mathrm{t} \text { landfill waste }\right)^{-1}\right)$. It should be noted that at the time of writing, there are plans to update the FCM-PCP municipal quantification tool ${ }^{12}$.

The USEPA WARM model was created to assist municipal waste planners in making better decisions with respect to GHG emission mitigation from waste 9 . The model allows the quantification of emissions from landfills (using a MC approach), composting, incineration and recycling. Due to the life-cycle perspective taken, emissions credits are provided using a system expansion approach that incorporates offsets. By expanding the system boundary to include an estimated quantity of emissions 
avoided due to a component of the waste management activity (i.e., electricity generation from LFG), the USEPA model reduces emissions allocated to the waste activity by that quantity (i.e., emissions that would have otherwise occurred had, for example, the electricity been produced from fossil-based electricity generation). Sources of credits in the WARM model include: 1) using recycled (rather than virgin) content; 2) electricity generated from waste management practices; 3) carbon stored in soil from compost; 4) sequestration of biogenic carbon in landfills. These all have varying degrees of uncertainty associated with them; for example the model assumes an infinite timeframe for the landfill credit though future disturbances to landfill sites, such as landfill mining, may oxidize this carbon (such as through combustion or biodegradation). Additionally, from a management perspective, credits can shift the focus away from current $\mathrm{CH}_{4}$ emissions, which is problematic as $\mathrm{CH}_{4}$ is a potent $\mathrm{GHG}$ with an intense, short-term effect on radiative forcing ${ }^{6}$.

The methodologies examined allow varying amounts of flexibility for considering jurisdictionspecific conditions. Generally speaking, average/default values are applied for the comparison of the models, leaving some uncertainty in the figures.

\section{METHODOLOGY}

\section{Greater Toronto Area (GTA)}

The GTA is comprised of five regional municipalities: City of Toronto, Peel, Halton, Durham and York. The GTA is selected as the study region in contrast to solely examining the City of Toronto, for two reasons; firstly, waste is a regional issue with waste management operations being utilized by multiple municipalities within the region. Secondly, this complements a study performed by Kennedy et al. on regional GHG emissions and follows their methodology of examining a major urban centre along with its neighbouring communities whose economies are interdependent ${ }^{4}$. In 2006, the population of the GTA was estimated at 5,556,182, with $45 \%$ of residents centrally located in the City of Toronto. It is estimated that, on average, GTA residents sent $210 \mathrm{~kg}$ of MSW to landfill per capita in 2005, compared to the national and provincial residential averages of 290 and $305 \mathrm{~kg}$, respectively (see Table 1) ${ }^{13,14}$.

Prior to the mid 1960s, waste management strategies were guided by a mélange of municipal policies across the GTA ${ }^{15,16}$. Incineration was the primary means of waste management up until the mid-1960s; however, incinerator capacity frequently did not match waste production. Up until 1965, emergency landfills set up in public ravines were used in the City of Toronto to handle the excess waste $^{16}$. In addition, private dumps, which often partook in open burning, were prevalent. In order to address this patchwork disposal system, large peri-urban landfills were planned and commenced 
operation in 1967. However, as a result of the diverse waste management schemes across the GTA, obtaining accurate waste disposal data from the era prior to large scale landfill sites is difficult.

The earliest landfill waste figures are from City of Toronto archives, where waste disposed in the four major regional landfills between 1971-1979 are available (Beare rd, South Thackeray, Brock West and Brock North) ${ }^{15}$. Landfilled waste data between 1955 and 1970 are extrapolated based on per capita waste produced in 1971 and census data. Waste data for odd numbered years between 1981 and 1989 are obtained from Metro Toronto Planning Dept publications (1981, 1983, 1985, 1987, 1989) and gaps between these data and 1989 - 1999 are linearly interpolated (Figure 1). Data from 1999 - 2005 are obtained from Kennedy and others, as well as from regional data ${ }^{17,18,19,20,21,22}$. All data obtained prior to 1999 includes industrial, commercial and institutional (ICI) waste; hence, a correction factor of 0.36 (representing the proportion of ICI waste reported in Ontario in 2006) is applied to these ${ }^{13}$.

A drop in the quantity of Peel landfill waste in 1993 is assumed, due to the introduction of a Waste-to-Energy incineration operation (assumed to have a capacity of accepting $80 \mathrm{kt}^{\text {of }}$ waste $\mathrm{yr}^{-1}$ ). A steep upward slope in the growth of waste emissions is observed during the 1980s. This is likely attributable in part to population growth, coupled with the closure of incinerators during that period. However, given that incinerators accounted for 200,000 tonnes of waste in 1981 and the rate of population growth does not seem to differ much from other decades, this may not provide a complete explanation. A similar spike is observed by Anderson, looking at Metro Toronto and industrial waste, however, waste production from the former City of Toronto (which represented the central component of the former Metropolitan area) did not rise as quickly, suggesting that this increase is mainly attributable to the Industrial, Commercial, and Institutional (ICI) sector, perhaps due to the closure of incineration facilities previously accepting this sector's waste ${ }^{16}$.

\section{Waste GHG Emissions Models}

Landfilling waste is the dominant treatment method in the GTA, followed by recycling, composting, incineration and $\mathrm{AD}$. The proportion of waste which is from single family housing compared with multi-unit dwellings is obtained from census data ${ }^{14}$. Parameters applied to the four methodologies and the two variations on IPCC 2006 are displayed in Table 2, along with applicable sources (some of which are discussed further in the specific methodologies below). Calculation methods for incineration- and composting-related emissions were only available in IPCC 2006 and USEPA WARM, while AD emissions calculations are only possible for the former; IPCC 1996 \& FCMPCP do not provide a means of quantifying these. For the waste composition calculations, 
differentiation is made between single family and multi-unit dwellings; these are taken from City of Toronto data and assumed to be uniform across the region (except for the Region of Peel incineration calculation; see GTA background above $)^{23}$. The smaller contribution of waste $>10$ years old to current emissions (see Results \& Discussion) validates this assumption.

Of the parameters listed above, default data are generally used with the exception of those relating to emission reduction credits discussed in the IPCC 2006 LC approach (specifically, average grid emissions and incineration electricity generation, which are calculated for GTA-specific conditions). Electricity generation from waste treatment options assumes a $47 \%$ conversion efficiency of total methane captured (using a reciprocating engine) and a lower heating value of $50 \mathrm{MJ} / \mathrm{kg}{ }^{24}$. Methane production is multiplied by capture efficiency to provide the figure for total weight of $\mathrm{CH}_{4}$ captured, with landfills that have received GTA waste are equipped with LFG capture systems (assumed to be collecting $75 \%$ of LFG) with electricity generation. GHG emission reduction credits (or offsets) are applied for electricity produced from treatment options and generation is assumed to be continuous ${ }^{21}$, allowing a 2005 provincial average emissions factor to be used.

Regarding specific treatment methods, it is assumed that no emissions result from backyard composting (assumed aerobically degraded). All green bin waste is assumed to be anaerobically digested at central processing facilities.

\section{FCM-PCP}

In order to assist municipalities to compile GHG inventories, a spreadsheet tool is provided entitled "Inventory Quantification Support Spreadsheet", which is based on PCP GHG software ${ }^{10}$. The calculation for annual GHG emissions is based on an emissions factor (see eq 1 below), and is assumed to be based on national average data, though this could not be confirmed. Using a simple "emissions factor" calculation in a GHG emissions system as complex as waste cannot provide the flexibility of the other more detailed methodologies described below. However, this is simply a preliminary figure for municipalities to use and it is of interest for comparison with other more rigorous methodologies.

GHG emissions $=t$ of waste landfilled $\bullet 0.4817 t \mathrm{CO}_{2}$ e $t$ of waste landfilled $\left(t \mathrm{CO}_{2} e\right)$

\section{IPCC 1996}

As stated earlier, the IPCC 1996 uses a MC approach for GHG emissions quantification. Emissions can be calculated using (adapted from IPCC 1996) ${ }^{8}$ :

$$
\begin{aligned}
& \mathrm{CH}_{4} \text { emissions }=\left(\mathrm{W} \cdot \mathrm{MCF} \cdot \mathrm{DOC} \cdot \mathrm{DOC}_{F} \cdot \mathrm{F} \cdot 16 / 12\right) \cdot(1-\mathrm{R}) \cdot(1-\mathrm{OX}) \\
& \quad\left(\mathrm{Gg} \mathrm{yr}^{-1}\right)
\end{aligned}
$$


where $W=$ total weight of waste deposited in landfills $\left(\mathrm{Gg} \mathrm{yr}^{-1}\right) ; M C F=$ Methane Correction Factor (for sanitary landfills $=1) ; D O C=$ Degradeable Organic Carbon; $D O C_{f}=$ Fraction $D O C$ dissimilated; $F=$ Fraction of $\mathrm{CH}_{4}$ in LFG; $R=$ Fraction of $\mathrm{CH}_{4}$ Recovered (i.e. LFG capture efficiency); $O X=$ Fraction $\mathrm{CH}_{4}$ Oxidation.

\section{IPCC 2006}

The IPCC 2006 method involves the most complex calculation of the four landfill methodologies examined. A first-order decay model (Scholl-Canyon model; Tier 2) approach is employed, using default parameters and region-specific landfill data. The WIP calculation uses sequential calculations each year, employing the eqs outlined below ${ }^{7}$ :

$$
\mathrm{DDOCm}=W \cdot \mathrm{DOC} \bullet \mathrm{DOC}_{f} \bullet \mathrm{MCF}
$$

where $D D O C m=$ mass of decomposable $D O C$ deposited

$$
\mathrm{DDOCma}_{T}=\mathrm{DDOCmd}_{T}+\left(\mathrm{DDOCma}_{T-1} \bullet e^{-k}\right)
$$

where $D D O C m a_{T}=D D O C m$ accumulated in a given year $(\mathrm{T}) ; D D O C m d_{T}=D D O C m$ deposited in year $\mathrm{T} ; k=$ reaction constant $\left[\ln (2) / \mathrm{t}_{1 / 2}\left(\mathrm{yrs}^{-1}\right)\right] ; \mathrm{t}_{1 / 2}=$ half-life of waste $(\mathrm{yrs})$

$$
\operatorname{DDOCm~decomp}_{T}=\operatorname{DDOCma}_{T-1} \bullet\left(1-e^{-k}\right)
$$

where $D D O C m$ decomp $_{T}=D D O C m$ decomposed in year $\mathrm{T}$

$$
\begin{gathered}
\mathrm{CH}_{4} \text { generated }=\mathrm{DDOC} \text { decomp }_{T} \bullet \mathrm{F} \cdot 16 / 12 \\
\mathrm{CH}_{4} \text { emitted }=\left(\mathrm{CH}_{4} \text { generated }-\mathrm{R}\right) \cdot(1-\mathrm{OX})
\end{gathered}
$$

Waste composition is assumed to be constant for historic data, and hence, the degradable organic carbon (DOC) content is the same for all years used for the WIP calculation. Disposal is assumed to be at the beginning of the year, with methane emissions calculated at year's end. DOC is weighted according to the IPCC 2006 fractions for waste components. Wastewater sludge deposited in landfills is assumed to be in the form of biosolids that are stabilized to the extent where further decomposition is negligible.

In year 0 (i.e., 1955), DDOCma ${ }_{T-1}$ and $D D O C m$ decomp $_{T}$ are assumed to be nil, giving a value of $D D O C m a_{T}$ that is simply the amount of decomposable DOC deposited in 1955. This was used as a basis for calculations in all following years. The reaction constant $(k)$ is estimated assuming boreal region under dry conditions using Environment Canada data on Toronto's mean annual precipitation and relating it to potential evapotranspiration ${ }^{25}$. 
A MC calculation is completed in the same manner (denoted IPCC $2006 \mathrm{MC}$ ), using the above eqs, except in this case year 0 is 2005, with a 100-year forecast for resulting methane emissions (a $75 \%$ LFG capture efficiency is assumed for the lifetime of the waste). This is assumed to be a sufficiently long forecast since by the year 2105, methane emissions are estimated to be below $25 \mathrm{tCO}_{2} \mathrm{e}$ year $^{-1}$ (Figure 2).

Calculations of IPCC 2006 for other disposal methods only require knowledge of total waste tonnage and composition (Tier 1). Equation 8 provides an estimate of emissions from fossil carbon from incineration. As only the Region of Peel treats waste through combustion, and this waste is generally sourced from multi-residential units, waste audits for Peel are used to quantify the relevant waste composition $^{19}$.

$$
\mathrm{CO}_{2} \text { emissions }\left(t \mathrm{CO}_{2} e\right)=\mathrm{MSW} \bullet \sum_{j}\left(W_{j} \bullet d m_{j} \bullet C F_{j} \bullet F C F_{j} \bullet O F_{j}\right) \bullet 44 / 12
$$

where $M S W=$ total wet weight incinerated, $\mathrm{Gg} \mathrm{yr}^{-1} ; W F_{j}=$ fraction of component $j$ in the $\mathrm{MSW} ; d m_{j}=$ dry matter in component $j$ (fraction); $C F_{j}=$ fraction of carbon in dry matter of component $j ; F C F_{j}=$ fossil carbon fraction in of component $j ; 44 / 12=$ conversion factor from $\mathrm{C}$ to $\mathrm{CO}_{2}$. All calculations for dm, CF and FCF used IPCC 2006 defaults.

The IPCC 2006 methodology suggests that both $\mathrm{CH}_{4}$ and $\mathrm{N}_{2} \mathrm{O}$ are released during the composting process (specifically large-scale operations, inferred from references cited within the IPCC guidelines), while emissions from residential-scale compost (i.e. home composting units) do not receive any explicit mention. Composting and $\mathrm{AD}$ calculations for $\mathrm{CH}_{4}$ and $\mathrm{N}_{2} \mathrm{O}$ emissions require only tonnage treated and IPCC defaults and are described in eq 9. According to this methodology, $\mathrm{N}_{2} \mathrm{O}$ emissions from anaerobic digesters are assumed to be negligible; IPCC 2006 cautions that more data on these emissions are needed. IPCC 2006 suggests using a 5\% leakage rate for AD facilities.

$$
\text { GHG emissions }\left(t \mathrm{CO}_{2} e\right)=\left[(\mathrm{M} \cdot \mathrm{EF}) \cdot 10^{-3}-\mathrm{R}\right] \cdot G W P_{100}
$$

where $M=$ wet weight of waste treated $(\mathrm{t}) ; E F=$ emissions factor $(\mathrm{kg} \text { (t waste treated) })^{-1} 4 \mathrm{for}^{\mathrm{C}} \mathrm{CH}_{4}$ compost; 0.3 for $\mathrm{N}_{2} \mathrm{O}_{\text {compost }} ; 1$ for $\left.\mathrm{CH}_{4 \mathrm{AD}}\right) ; R=$ gas recovered ( 0 for composting; $95 \%$ for $\left.\mathrm{AD}\right) ; G W P_{100}=$ Global Warming Potential based on a 100-year timeframe $\left(25 \text { for } \mathrm{CH}_{4} ; 298 \text { for } \mathrm{N}_{2} \mathrm{O}\right)^{6}$.

\section{USEPA WARM}

Tonnage, composition and diversion rate details are integral to the usage of the WARM model. Using waste audits and diversion rates for 2005, data is entered for the various required component streams. Stewardship Ontario data are categorized according to the waste inputs available in the USEPA model $^{9,23}$. The data and method of application are available in the supplemental materials. 


\section{Life Cycle-based Approach}

A life cycle-based approach (IPCC 2006 LC) is used to include more of the upstream (life cycle) GHG emissions associated with waste management practices in the GTA for 2005 using the IPCC 2006 MC method, with the functional unit being waste managed in 2005 . While a larger proportion of life cycle emissions associated with waste management are included in this method than with the IPCC 2006 MC, a full life cycle inventory analysis is not completed. The boundaries for the IPCC 2006 LC approach are presented in Figure 3, using credits/emissions applicable to scope of a municipal inventory (use of incineration residues for fertilization in forestry has been reported by Toller et $\mathrm{al}^{26}$ ). Specifically, emissions included are those related to the collection and transportation of waste to treatment sites and those associated with the treatment options themselves. The exclusion of upstream emissions of fuels will have a negligible impact on results, since transportation of waste materials is generally a lower proportion of total waste-related emissions (Mohareb et al estimate a contribution of $8 \%$ of gross emissions or $15 \%$ of net emissions including credits for recycling) and combustion is the primary source of these emissions when diesel is used as a fuel ${ }^{27,28,29}$. Emission reductions from co-products directly resulting from on-site activities of treatment methods (i.e. electricity production from incineration) are included within the LC boundary as well.

IPCC 2006 is selected for this approach as it allows for the quantification of emissions from landfill, AD, incineration and large-scale composting. Using an IPCC method with some scope for life cycle emissions also allows comparison of a designated emissions inventorying with USEPA WARM (which is explicitly stated to be incompatible with emissions inventorying), as it uses a life cycle approach. A point of note is that WIP cannot be used as the means to quantify emissions from landfilled waste as this would not conform to the temporal boundary set by examining waste collected within 2005.

No GHG emissions reduction credits for recycling are allocated to GTA municipalities. While recycling credits may be suitable on a national level, there is little certainty that materials diverted for recycling will actually be processed and used within the same spatial boundary being assessed ${ }^{30}$. From a life cycle inventory perspective, the location of an activity would not, in itself, provide justification for exclusion, but this was deemed appropriate in the context of municipal inventories; since this study focuses on emissions and credits applicable to municipalities based on policy decisions, exclusion of these credits is reasonable as the decision on reuse of recycled material is beyond municipal jurisdiction. In addition to the uncertainty associated with where the co-products will be used, Finnveden illustrates 
complications that arise when materials are not recycled directly into the same product (termed openloop recycling) ${ }^{31}$. Allocation procedures differ for the emissions related to the original product and those incorporating recycled content. Some estimates on potential credits associated with recycling are provided in the "Results \& Discussion" section.

Emissions reductions from co-products serving as fertilizer/soil conditioner are also excluded due to the uncertainty in their destination and final use (i.e. potential contamination may prevent their usage). Finnveden et al suggest that GHG emission benefits from fertilizer displacement from anaerobic digestion and composting are also likely $\operatorname{small}^{27}$.

Emissions from capital infrastructure are ignored; there is precedence for this as Cleary states that only three of the 20 waste LCA studies he reviewed included these emissions ${ }^{32}$. However, energy requirements from operations are considered. Denison provides a figure for net energy generated for incineration, while landfill operations utilize roughly $15 \%$ of energy generated for internal operations, which is applied to the IPCC 2006 methodology ${ }^{33,34}$. It is assumed that the latter figure is likely a mixture of diesel, electricity and natural gas in the GTA; however for simplicity, a $15 \%$ penalty is applied to landfill gas electricity generation and is also applied to electricity generation at AD facilities (it should be noted that this penalty would be much greater if diesel had been used exclusively). Composting operations energy requirements are assumed to be negligible.

The IPCC 2006 LC approach examined in this work includes transportation for waste and grid emissions factors (applied during system expansion to include for offsets for electricity production. Transportation distance calculations follow the methodology used by Mohareb, using distances from the approximate geographic centre of an urban area (as opposed to city hall) to landfills, incinerators, anaerobic digesters and material recovery facilities (for recycling) ${ }^{28}$.

Grid emissions factors applied in the system expansion approach for landfill, AD and incineration operations represent the marginal emissions that would have otherwise occurred from the electricity generation. Finnveden suggests that a marginal source of electricity (coal) is displaced by electricity from waste, whereas Cleary observed an even split in 12 studies between the use of marginal and average electricity source emissions factors ${ }^{27,32}$. In a situation where $\mathrm{CH}_{4}$ storage is possible (or $\mathrm{CH}_{4}$ is flared when demand does not exist) and is used only to meet a fluctuating load or as spinning reserve for the electrical grid, use of the emissions factor for the displaced marginal generation is logical. Conversely, if LFG is combusted as produced then it supplies baseload generation and use of the average grid emissions factor is preferred. 


\section{Sensitivity Analysis}

Selection of the parameters described in Table 2 is made based on default data used in other literature, but regional specifications (such as factors related to the GTA's climatic zone) are applied where available. However, there is some uncertainty in many of these quantities and this is addressed in a sensitivity analysis.

Uncertain treatment-specific factors considered in this study include oxidation of $\mathrm{CH}_{4}$ (landfill), concentration of $\mathrm{CH}_{4}$ in LFG, carbon content of waste (landfill, incineration), fraction of carbon dissimilated (degraded in landfills), reaction constant ( $k$; relevant to first-order decay models for landfills) and methane leakage ( $\mathrm{AD}$, landfill with $\mathrm{LFG}$ capture). Oxidation of $\mathrm{CH}_{4}$ in $\mathrm{LFG}$ due to use of specialized covers (other than clay) has reduced emissions from $10-100 \%$, varying due to site and climatic conditions ${ }^{35}$. An Alberta, Canada study suggested that the rate of oxidation is dependant on $\mathrm{CH}_{4}$ flow rate, suggesting value of $k$ may influence oxidation ${ }^{36}$. The USEPA and IPCC (1996 and 2006) both make the assumption of $10 \%$ oxidation using aerating covering material. While this may seem low in light of the range suggested above, the more conservative estimate is prudent without site specific data.

LFG $\mathrm{CH}_{4}$ fractions are also somewhat uncertain, with the IPCC default being $50 \%$ while the fraction recorded at Brock West, Beare Rd and Keele Valley landfills in 2001 were roughly 40\%, 45\% and $47 \%{ }^{37}$. Impacts of modifying $\mathrm{LFG} \mathrm{CH}_{4}$ concentrations are assessed in the sensitivity analysis.

The leakage rate of LFG is also a point of contention in literature. In the WARM model, a default assumption of $75 \%$ capture rate is assumed as the national average efficiency. The Keele Valley landfill site (GTA) estimates a collection efficiency of between 85-90\% (high, but not infeasible according to Barlaz et al), while Mohareb reports $40 \%$ for the Trail Rd landfill in the Ottawa Region $28,38,39$. A value of $50 \%$ is selected for sensitivity analysis versus the $75 \%$ baseline suggested by the $\mathrm{USEPA}^{40}$.

The carbon content of waste is region-specific and can be approximated using waste audits (such as those provided by Stewardship Ontario) and default values of carbon contents of various waste

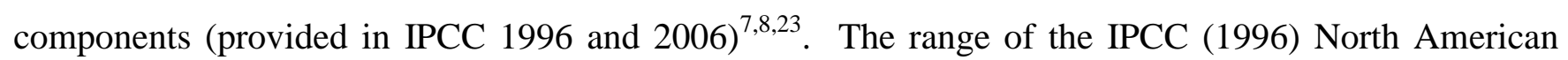
values is used for the sensitivity analysis.

The fraction of biogenic carbon that can actually be dissimilated is also a matter of debate. Barlaz suggests that roughly $40 \%$ of carbon in MSW does not decompose under anaerobic conditions, while the IPCC default suggests using a value of $50 \%$ of total degradable carbon ${ }^{7,41}$. 
The reaction constant, $k$, is sensitive to the climatic conditions and composition of the waste deposited in landfill, amongst other factors. For example, some landfills have been operated as bioreactors, with recirculation of leachate in order to increase the reaction constant ${ }^{42}$. This parameter has not been assessed since the latter has no impact on total emissions (such as for the MC method).

\section{RESULTS \& DISCUSSION}

\section{Model Comparison - Landfill Waste}

As the principle source of GHG emissions, it is of most interest to compare the results for landfill emissions from the six approaches examined (Figure 4). Four MC calculations are provided, as well as the IPCC 2006 LC and the IPCC 2006 WIP calculation. FCM-PCP, IPCC 1996 \& IPCC 2006 (MC \& WIP) figures given below are gross site emissions (without transportation emissions or offsets for electricity generation), while WARM and IPCC 2006 LC calculations are net emissions. This is because WARM and IPCC 2006 LC incorporate the offsets, as well as transportation emissions. Total landfill GHG emissions estimates vary from $~ 556 \mathrm{kt}$ (FCM-PCP) to a net carbon sink of $53 \mathrm{kt}$ (WARM).

Figure 4 can be used to illustrate some of the strengths, weaknesses and applications of each model. Firstly, while the FCM-PCP model likely overestimates GHG emissions due to its inflexibility and relatively high landfill waste emissions factor $\left(0.4817 \mathrm{t} \mathrm{CO}_{2} \mathrm{e}(\mathrm{t} \text { waste })^{-1}\right.$, compared with $0.302 \mathrm{t}$ $\mathrm{CO}_{2} \mathrm{e}$ (t waste) $)^{-1}$ from the IPCC $2006 \mathrm{MC}$ ) it can be considered a reasonable "first guess", given that emissions from the IPCC 2006 MC method are within the same order of magnitude.

Secondly, IPCC MC methodologies provided similar results (with the 1996 calculation being 5\% greater), suggesting that professional judgment be used in considering whether to employ the slightly more detailed waste stream quantification required in the IPCC 2006. As well, if one were to simply apply the median value of the default DOC range provided for North America in IPCC $1996(0.18-0.21$; i.e. using a DOC value of 0.195), the difference compared with the IPCC $2006 \mathrm{MC}$ method increases to $18 \%$. Using the median value could provide an acceptable approximation in this case if one were willing to tolerate a difference of this magnitude. This allows the quantification of the waste MC emissions without having to quantify waste stream components using audit data, if municipal waste audit data were unavailable or difficult to obtain. Assurance can be taken from greater diligence; however, the degree of accuracy that is necessary and cost limitations should be factored into the decision if a waste audit will be required to obtain waste stream information. 
Thirdly, differences are evident in IPCC 2006 WIP and MC estimates, though WIP can be given more weight from an inventorying perspective as it quantifies emissions in the inventory year, rather than projecting future emissions (there is uncertainty in the historic mass of waste and its composition applied to WIP, as well). It must be noted that the correspondence of these two values is case specific (as it would be in any of these approaches); landfilled waste tonnage has been relatively stable during the past decade (a slight decline in recent years gives a lower MC value), coupled with other parameters being assumed constant (such as LFG capture for MC or DOC for WIP), resulting in the similar quantities obtained. Uncertainty in the future landfill management practices clouds the accuracy of emissions quantified by MC.

From an economic perspective (i.e., discounting), future emissions may have less value than GHGs released at present. From a climatic perspective, and within in the context of a municipality with an increasing organics diversion rate, using the $\mathrm{MC}$ projection for an inventory underestimates $\mathrm{CH}_{4}$ emissions occurring at present. However, developing countries that increasingly use sanitary landfills for waste disposal will experience a rise in waste-related GHG emissions ${ }^{7}$; if a MC method is selected for inventorying purposes rather than WIP, a greater emission estimate will result. It follows that WIPapproach quantification would give a lower estimate when compared to MC due to the lower contribution from waste deposited in previous years that may have occurred otherwise if open dumping or a semi-aerobic disposal were used,.

The USEPA WARM model is a clear outlier of the models assessed. This is principally due to the provision of carbon credits for the sequestration of organic carbon. Under aerobic conditions, it is assumed that biogenic carbon breaks down completely, releasing atmospheric $\mathrm{CO}_{2}$ which had been previously captured during photosynthetic processes. However, as stated previously, not all carbon is dissimilated in the anaerobic environment present in an undisturbed landfill ${ }^{7,38}$. Hence a significant carbon sink, compared to the aerobic degradation base-case, is created in landfills. When this is coupled with emissions offset by electricity generation from captured LFG, a negative GHG emission scenario results.

The concern regarding difficulty in obtaining accurate historic waste data may be of little importance. The IPCC suggests that waste data from at least 10 years prior are required for use of the 2006 method. Looking at the contribution from waste deposited prior to 1995 , this is roughly $12 \%$ of 2005 WIP emissions, given the methane generation rate calculated for the GTA. This contribution will increase for regions where the reaction constant $(k)$ is lower (drier climates or where greater proportions 
of slower degrading materials such as wood and paper waste are landfilled). For example, if using upper estimates for half-life of waste in landfills located in boreal/dry climates, the contribution of waste older than a decade would increase to $16 \%$. For warmer, wetter climates the effect of this earlier data will diminish, adding greater incentive for cities to use the WIP approach when used for inventorying purposes. In cases where obtaining historic waste disposal data is difficult, estimations for waste deposited based on population trends (using per capita waste) will likely meet the requirements of most applications.

There is certain value for all of the LFG models assessed above, such as ease of use (FCM-PCP) or increased rigor (IPCC 2006 WIP). The simplicity provided by the MC models can definitely be appreciated in circumstances where time or resources are constraints; however, greater adherence to inventorying goals (i.e., consistent emissions temporal boundaries) is achieved with the IPCC 2006 WIP model since there is more parameter flexibility and fewer assumptions inherent in its design.

\section{Life Cycle-based Approach to Waste Emissions}

The IPCC 2006 LC approach is used in order to quantify some key credits that are within municipal spatial boundaries and further emissions attributable to each waste management activity. This approach underlines the relative importance of landfill emission quantification, as LFG emissions provide the greatest share of the total.

Under the IPCC 2006 LC approach, gross emissions from waste management practices in the GTA are shown in Table 4, using the MC calculation for landfill. Total emissions in 2005 using this methodology were estimated to be $509 \mathrm{kt} \mathrm{CO}_{2} \mathrm{e}$. When applying a credit for carbon emissions offset by

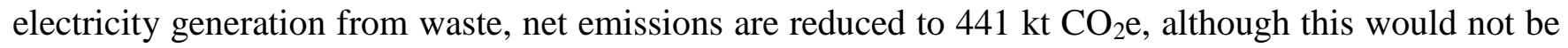
included in standard GHG emission inventorying practice (not to be confused with life cycle inventory practice); while emissions may indeed be reduced, credits for emissions offsets are not applied towards totals in GHG inventories, such as those provided in national inventory reports ${ }^{7}$.

Table 4 details the specifics regarding gross and net emissions for each treatment option. The data are in agreement with Finnveden and Mohareb in that transportation-related emissions have a relatively minor impact on the total (contributing less than $10 \%$ to total emissions) ${ }^{27,28}$. Even if total transportation distance is doubled to account for any underestimation made in distance travelled to waste facilities, it would only contribute slightly more than $13 \%$ to total net emissions.

$\mathrm{AD}$ is the only management option that produces net negative emissions (direct minus electricity offsets); if transportation emissions were disaggregated and added to AD facilities emissions, net 
emissions would be revised to roughly zero. While one might expect higher emissions due to the relatively high leakage rate suggested by IPCC 2006 guidelines, the low emissions values resulting from default parameters are likely due to the relatively high moisture content of the waste deposited in AD (predominantly source separated organics) when compared to landfilled waste which includes components with higher carbon contents (e.g. greater proportion of forestry products). Composting provides a very high emissions result in relation to incineration and landfilling, especially when comparing net emissions. Composting emissions could be even greater when considering that backyard composting is suggested to result in $\mathrm{N}_{2} \mathrm{O}$ and $\mathrm{CH}_{4}$ emissions that would not be negligible; Amlinger et al suggest that each tonne of wet waste could result in the emission of $76-187 \mathrm{~kg} \mathrm{CO}_{2} \mathrm{e}$ (or up to $0.45 \mathrm{~kg}$ $\mathrm{N}_{2} \mathrm{O}$ and $2.2 \mathrm{~kg} \mathrm{CH}_{4}$ per tonne of wet waste deposited in backyard composting units) ${ }^{43}$. It is also possible that properly managed composting systems would have lower GHG emissions than have been estimated using IPCC default emissions factors.

Additionally, relatively high GHG emissions are associated with incineration. When one considers that, for direct (excluding transportation and electricity generation) emissions, $90 \mathrm{kt}$ of incinerated waste resulted in $29.8 \mathrm{kt}$ of gross GHG emissions and 1,150 kt of landfilled waste resulted in IPCC $2006 \mathrm{MC}$ calculation of $348 \mathrm{kt}$ of GHG emissions, emissions per unit of waste treated are $9 \%$ higher for incineration compared with landfill. When including offsets for energy generation for both landfill and incineration, the net emissions from landfills are only $11 \%$ higher per tonne of waste treated. This is a conservative estimate given that the Ontario government has proposed the replacement of all coal-fired generating stations with renewable and natural gas-fired generation by 2014, as evidenced by the expected decommissioning of nearly $1 / 3$ of existing coal-fired generating capacity in $2010^{44}$. If using a lower emissions factor (i.e. reducing the emissions factor by $1 / 3$ ), landfill emissions are only $4 \%$ higher than incineration per tonne of waste treated.

It may be of interest to briefly examine the emissions reductions potential from recycling, although this was beyond the scope of the LC approach. Mohareb et al suggest a virgin material displacement credit of approximately $1.04 \mathrm{t} \mathrm{CO}_{2} \mathrm{e}$ per tonne of mixed material recycled, while the USEPA suggest $0.85 \mathrm{t} \mathrm{CO}_{2} \mathrm{e}$ (excluding transport and process non-energy), giving a credit of 464 and $380 \mathrm{kt} \mathrm{CO}_{2} \mathrm{e}$, respectively, for the nearly 447,000 tonnes of waste diverted from the GTA for 2005 ${ }^{28,40}$.

\section{Comparison of Net GHG Emissions}

IPCC 2006 MC and the WARM model were both used to calculate net annual GHG emissions (including offsets from electricity generation and emissions from transportation) for different waste 
treatment options (Figure 5). Net emissions from landfills increase marginally when using a more conservative figure for the reciprocating engine efficiency; Lombardi suggests an efficiency of 35\%, which would cause the net efficiency for the IPCC 2006 methods to increase by $5 \%$.

The reduction in net emissions is far more substantial for the WARM model than IPCC. WARM provides further credits from the following: 1) A larger credit for electricity offsets is assumed due to the prevalence of coal-fired generation in the US (average emissions factor of $1014 \mathrm{~g} \mathrm{CO}_{2} \mathrm{e}(\mathrm{kWh})^{-1}$ is used and cannot be adjusted), while the IPCC calculation for the GTA scenario examined uses the 2005

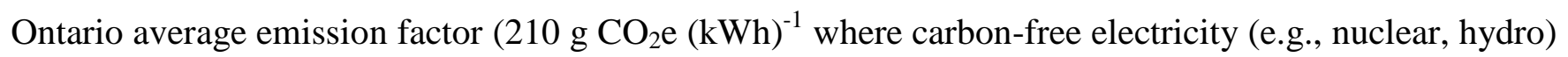
contributes a greater proportion ${ }^{1}$ ); 2) A significant credit is applied to landfills due to undegraded biogenic carbon; 3) Soil carbon credits are provided for composting (and no $\mathrm{CH}_{4}$ or $\mathrm{N}_{2} \mathrm{O}$ emissions penalty). If credits for LFG electricity generation are removed, USEPA WARM suggests an $80 \mathrm{kt} \mathrm{CO}_{2}$ emissions source for landfill waste disposal will result.

The IPCC inventorying approaches calculate methane emissions by assuming that only a portion biogenic carbon deposited in landfills are degraded under anaerobic conditions (using the fraction of carbon dissimilated, $\left.\mathrm{DOC}_{\mathrm{f}}\right)^{7,8}$. If one were to assume that all undegraded biogenic carbon from IPCC scenarios would be have been oxidized under aerobic conditions, the carbon sink provided by the anaerobic landfill conditions for waste deposited in 2005 is calculated to be $170,300 \mathrm{t} \mathrm{CO}_{2} \mathrm{e}$ using the IPCC $2006 \mathrm{MC}$ method; this would result in a net emissions value of 120,700 t $\mathrm{CO}_{2} \mathrm{e}$, still greater than the WARM figure. Greater flexibility on which sinks to incorporate and parameter values used in the WARM model would improve accuracy and applicability.

The discrepancy in compost emissions also comes from the high default values of the IPCC 2006 $\mathrm{CH}_{4}$ and $\mathrm{N}_{2} \mathrm{O}$ emissions factors, in addition to the application of carbon credits in the WARM scenario. As stated earlier, Hobson et al $^{46}$ suggest that GHG production is likely when household waste is deposited in windrows, especially $\mathrm{CH}_{4}$. Quantities of $\mathrm{N}_{2} \mathrm{O}$ may be lesser; however, due to its greater global warming potential over a 100-year time frame, its effect is more prominent (75\% of compostingrelated GHG emissions). More research is needed on the production of these two important GHGs from the composting of MSW in windrows in order to determine the most suitable approach.

\section{Uncertainty \& Sensitivity Analysis}

As outlined in the background section, many variables in the quantification of GHG emissions from waste are uncertain. Table 5 provides a number of uncertain variables within the methodology, along with the corresponding sensitivity of ranges for these variables according to literature or IPCC 
ranges (see Methodology for explanation of parameter selection). There is a focus on landfill-related emissions due to their relative significance compared to other emissions sources and the ubiquity of their quantification across multiple methodologies. The FCM-PCP eq does not allow any modifications of parameters other than waste deposited in landfills, which is a relatively certain quantity, and hence is not examined.

LFG capture efficiency has the greatest impact on landfill GHG emissions of those demonstrated above, with at least a doubling of emissions from a $1 / 3$ reduction in LFG collected.

By applying waste audits from the City of Toronto, degradable carbon content was estimated to be $16.1 \%$ and $16.9 \%$ using default data from IPCC 2006 and 1996, respectively, for carbon content for waste stream fractions. This figure varies based on waste composition (i.e., greater organic content gives a greater degradable carbon content). The IPCC provides a range of DOC in North American waste of $18-21 \%$. The high end of this range would provide an increase in landfill GHG emissions by nearly $25 \%$.

Variation of oxidation potential of landfill cover is examined using data provided by Stein and Hettiaratchi, who report a methane oxidation rate of $20 \%$ at a flow rate of $400 \mathrm{~g} \mathrm{CH}_{4}\left(\mathrm{~m}^{2}-\mathrm{day}\right)^{-1}{ }^{36}$. Sensitivity to an increase of $100 \%$ of the amount of $\mathrm{CH}_{4}$ oxidized reduced overall GHG emissions by $10 \%$. Lou \& Nair suggest oxidization of $\mathrm{CH}_{4}$ in landfill cover can range from negligible to $100 \%$, so importance should be placed on quantifying this value accurately ${ }^{35}$. It is hence of interest to use site specific measurements of these parameter for reliable inventorying.

LFG capture efficiency, degradable carbon content, oxidation rate, fraction dissimilated and $\mathrm{CH}_{4}$ content of LFG are examined in Table 6, based on the uncertainty demonstrated from literature and methodologies. Values are grouped into quantities that increase emissions and those that reduce emissions, providing a high and low case of each. The range of values vary substantially, as demonstrated by the high case for the IPCC 2006 model which is more than $450 \%$ that of the low case.

\section{Assessment of Models}

A summary of key model features is presented in Table 7. As stated in the introduction, those involved in urban emissions inventorying use a variety of models in their efforts to quantify GHG emissions attributed to activities of residents within their municipalities ${ }^{4}$. After examining the issues associated with the methodologies presented above, a principal categorization can be made; MC models are most valuable from a planning standpoint due to their predictive nature while the WIP model used in IPCC 2006 is most appropriate for conducting emissions accounting (emissions reduction credits for 
electricity generation must be neglected when reporting for the purpose of inventorying as inventories aim to quantify direct sources and sinks, not assumed derivative impacts). Since planning decisions can alter the values provided by MC models, they have limited usefulness from a reporting standpoint due to their greater degree of uncertainty. However, MC models can be helpful in quantifying the effects of certain landfill management decisions (i.e., measures to reduce LFG emissions) and for evaluating impacts on waste diversion from a global warming perspective (i.e., impacts from diverting waste to incineration). A WIP model can be used to provide similar information to planners, however it is temporally constrained to emissions in the inventory year rather than the entire lifespan of waste deposited in a given year. An additional attraction towards the MC approach comes from its relative simplicity, as data requirements for the WIP model can seem onerous.

As discussed in the "Model Comparison" section, there are circumstances where WIP and MC may coincide; if waste deposited in landfills has been relatively stable for recent years and similar parameters are used, the two methods will tend to agree with one another. If however, there has been a marked decline in waste being landfilled (examples being the introduction of an incinerator or new diversion programs to process organics), the WIP model will exceed MC. Conversely, if there is an increase in waste deposited in landfills (possible causes being the closure of an incinerator or reduced usage of aerobic waste treatment options), emissions from the MC method would exceed WIP. Greater complication in this relationship will be observed if projected values for parameters in the MC model such as oxidation, LFG capture efficiency and electricity generation (if considering offsets) differ from those employed in a WIP model.

USEPA WARM is unique in its consideration of both carbon emissions and sinks. This provides a simplified method for gaining insight into the carbon balance of waste operations. The developers of the model directly state that the tool should not be used in inventorying or accounting activities. While providing interesting information, various constraints limit rigor, such as those on recyclable material inputs (\% virgin: \% recycled), efficiency of energy conversion to electricity, oxidation from landfill cover and grid emission factor. Examining the WARM method for composting emissions quantification, $\mathrm{N}_{2} \mathrm{O} / \mathrm{CH}_{4}$ emissions are ignored, which is contrary to research presented in other literature ${ }^{43,46,47,48}$. Considering these limitations and the credits provided for undegraded carbon, it is unbalanced to compare absolute quantities obtained from WARM with other landfill MC and composting approaches. It may still be of interest to compare variation in WARM with other models, keeping in mind that the results are relative to the limitations imposed by each. 
The other three MC methodologies (FCM-PCP, IPCC 1996 \& 2006) vary in thoroughness. As stated earlier, due to the rigidity of the FCM-PCP model, it can only be considered a simplified first step to LFG emissions quantification. Additionally, the FCM-PCP tool calculates only emissions associated with landfill disposal and provides no allowance for including those from composting or incineration, which added over 100kt $\mathrm{CO}_{2} \mathrm{e}$ of emissions to the IPCC 2006 total in the GTA example. Allowing for the input of other waste-related variables, such as those mentioned above, will improve this approach. The IPCC 1996 MC landfill calculation is simpler than what was performed for IPCC 2006, as the former aggregated various organic components of waste streams to a greater degree than latter. The difference in the results from the two methods was roughly $7 \%$, which may be acceptable for purposes where such a disparity in approximations is sufficient.

The IPCC 2006 methodology can be improved through greater research on emissions factors and by the inclusion of guidelines on emissions from small-scale composting, however the pursuit of higher tier methods by cities would also address some of the uncertainty. Whether or not this endeavor is relevant to cities that may not have the means to pursue higher tiers is a matter for debate. An ideal approach for municipalities would include climate-specific emissions factors or methane generation reaction constants, site-specific recovery efficiency and oxidation data, and region-specific waste composition. The IPCC 2006 method could also be improved through further research on the fraction of carbon dissimilated in landfills and composting emissions.

Ultimately, the use of the MC methods for GHG inventory work must be avoided. It is suggested that 10-years of historical data with default IPCC 2006 coefficients be used to provide the most accurate picture of emissions in an inventory year, rather than quantifying future emissions which are far more uncertain. If 10-years of data are not available, landfilled waste can be extrapolated using an average waste per capita figure (or the oldest figure available) for city/region.

\section{CONCLUSIONS}

Empirical data are always ideal in quantifying GHG emissions from waste. However, if measured data are unavailable, modeling approaches can provide an estimate of emissions within the inventory year. In instances where data and parameters are more uncertain for a WIP approach, MC models can be used in GHG inventorying, though they are more appropriate when used for planning purposes. It is important to obtain earliest possible annual landfill disposal data (composition and tonnage) to ensure greater accuracy of IPCC 2006 WIP calculations; however, this should not be a barrier to attempting WIP quantification. 
As landfilled waste often represents the largest single urban emissions source managed by municipal governments, it is also an opportunity for GHG reductions. In proper accounting of these emissions, the best approach would be to use the IPCC 2006 methodology for quantification and gauging the impacts of waste management decisions. This approach also provides the means to assess emissions from all waste management options examined here, unlike the other methodologies assessed.

Without standardizing the methodology selected for corporate waste GHG emissions inventorying, it is inappropriate to compare these emissions between cities. If it is assumed that IPCC 2006 WIP provides the most accurate estimate for LFG emissions inventorying, deviations by the other models for landfills would be 13\%, 114\% and 49\% for IPCC 1996, USEPA WARM and FCM-PCP, respectively. When comparing waste emissions between cities, care must be taken to assess the methodology used and the selection of major parameters in each case. The same can be for decisionmaking related to treatment options.

In selecting a model for waste GHG measurement, five primary considerations affect the decision making process: 1) Assessment of disposal versus diversion practices (WIP vs. MC); 2) Motivation behind quantification (formal inventorying vs. planning); 3) Data quality / availability; 4) Acceptance and applicability of model assumptions / key inputs; and 5) Proportion of total (direct and indirect) emissions categories to be included.

Cities will likely continue to be leaders in efforts to address anthropogenic climate change, especially in the absence of binding international agreements or strong, unilateral action by national or state/provincial governments. Through diligent examination of the various quantification methods for municipal emissions, the most appropriate tool may be selected for successfully targeting important emissions sources on the path to a low carbon future. 


\section{References:}

1. Environment Canada. National Inventory Report: Greenhouse Gas Sources and Sinks in Canada, 1990 - 2007, 2009. http://www.ec.gc.ca/pdb/ghg/inventory_report/2007/som-sum_eng.cfm Accessed Oct. 8, 2009.

2. USEPA. Inventory of US Greenhouse Gas Emissions, 1990 - 2008, 2010. http://epa.gov/climatechange/emissions/usinventoryreport.html, Accessed May 20, 2010.

3. City of Toronto. Greenhouse Gases and Air Pollutants in the City of Toronto, 2007. http://www.toronto.ca/teo/pdf/ghg-aq-inventory-june2007.pdf, Accessed October 12, 2009.

4. Kennedy, C.; Ramaswami, A.; Carney, S.; Dhakal, S. Greenhouse Gas Emissions Baselines for Global Cities and Metropolitan Regions, 2009. http://siteresources.worldbank.org/INTURBANDEVELOPMENT/Resources/3363871256566800920/6505269-1268260567624/KennedyComm.pdf, Accessed May 20, 2010.

5. Kennedy C.; Bristow D.; Derrible S.; Mohareb E.; Saneinejad S.; Stupka R.; Sugar L.; Zizzo R.; McIntyre B. Getting to carbon neutral: A review of best practices in infrastructure strategy. In Proceedings of the Fifth Urban Research Symposium, Marseille, France, June 28-30, 2009. http://web.worldbank.org/WBSITE/EXTERNAL/TOPICS/EXTURBANDEVELOPMENT/0,,co ntentMDK:22446625 menuPK:360757 pagePK:210058 piPK:210062 theSitePK:337178,00.ht $\underline{\mathrm{ml}}$, Accessed May 20, 2010

6. IPCC. Climate Change 2007: The Physical Science Basis. Contribution of Working Group I to the Fourth Assessment Report of the Intergovernmental Panel on Climate Change. Solomon, S., D. Qin, M. Manning, Z. Chen, M. Marquis, K.B. Averyt, M. Tignor and H.L. Miller, Eds. Cambridge University Press, Cambridge, United Kingdom and New York, NY, USA, 2007 - See Figure 2-22.

7. IPCC. Guidelines for National Greenhouse Gas Inventories, Volume 5 - Waste; Geneva, 2006.

8. IPCC. Revised 1996 IPCC Guidelines for National Greenhouse Gas Inventories, Module 6Waste; Geneva, 1996.

9. USEPA. WAste Reduction Model (WARM), 2009. http://www.epa.gov/climatechange/wycd/waste/calculators/Warm_home.html, Accessed Nov 2, 2009 
10. Federation of Canadian Municipalities. Inventory Quantification Support Spreadsheet, 2009. http://www.sustainablecommunities.fcm.ca/files/Capacity_Building__PCP/GHG-inventoryquantification-spreadsh.xls-En.xls, Accessed Oct. 10, 2009

11. IPCC-NGGIP. IPCC Task Force on National Greenhouse Gas Inventories, 2009. http://www.ipcc-nggip.iges.or.jp/, Accessed Sept 17, 2009.

12. Connor J. ICLEI Canada, Toronto, ON. Personal Communication, June 2010.

13. Statistics Canada. Waste Management Industry Survey - Business and Government Sectors. Catalogue \#: 16F0023X. Ottawa, 2008.

14. Statistics Canada. 2006 Community Profiles, 2010. http://www12.statcan.ca/censusrecensement/2006/dp-pd/prof/92-591/index.cfm?Lang=E, Accessed May 17, 2010.

15. City of Toronto Archives. Solid Waste Management in Metropolitan Toronto - An Outline of the Function and Facilities of the Works Department. File number 51. 1980.

16. Anderson R. Waste Disposal in Toronto's Past. In Environmental geology of urban areas; N. Eyles Ed. Geological Association of Canada: St. John's, Nfld, 1997. pp 323-330.

17. Kennedy, C.; Cuddihy, J.; Engel-Yan, J. The changing metabolism of cities. J. Ind. Ecol. 2007, $11,43-59$.

18. City of Toronto. Residential Waste Diversion Rate, 2005. http://www.toronto.ca/garbage/residential-diversion.htm. Accessed February 2008.

19. Barton T. Region of Peel, Mississauga, ON. Personal Communication, November 2009

20. Darnell-Omotani, L. Region of York, Newmarket, ON. Personal Communication, November 2009

21. Watson, J. Region of Halton, Oakville, ON. Personal Communication, November 2009.

22. Durham Region. Waste Reports, 2009. http://www.region.durham.on.ca/extcontent.asp?nr=/departments/works/waste/wastgeninfo.htm

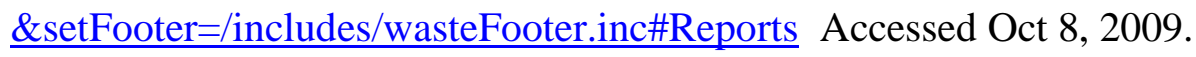

23. Stewardship Ontario. Toronto Waste Audits, 2005-2006, 2009.

http://www.stewardshipontario.ca/bluebox/eefund/projects/audits/waste_audit.htm, accessed Oct 23, 2009.

24. Harvey, L.D.D. Energy and the New Reality - Volume 1; Earthscan: London. 2010.

25. Environment Canada. Canadian Climate Normals or Averages, 1971-2000, 2008. http://climate.weatheroffice.gc.ca/climate_normals/index_e.html Accessed Nov 1, 2009 
26. Toller, S.; Kärrman, E.; Gustafsson, J. P.; Magnusson, Y. Environmental assessment of incinerator residue utilisation. Waste Manage. 2009, 29, 2071-2077.

27. Finnveden, G.; Johansson, J.; Lind, P.; Moberg, A. Life cycle assessment of energy from solid waste - Part 1: General methodology and results. J. Clean. Prod. 2005, 13, 213-229.

28. Mohareb, A. K.; Warith, M. A.; Diaz, R. Modelling greenhouse gas emissions for municipal solid waste management strategies in Ottawa, Ontario, Canada. Resour. Conserv. Recycling 2008, 52, 1241-51.

29. MacLean, H. L.; Lave, L. B. Life Cycle Assessment of Automobile/Fuel Options. Environmental Science and Technology 2003, 37, 5445-5452.

30. Cleary J. Department of Geography, University of Toronto, Toronto, ON. Personal Communication, Oct 2009.

31. Finnveden, G. Methodological aspects of life cycle assessment of integrated solid waste management systems. Resour. Conserv. Recycling 1999, 26, 173-187.

32. Cleary J. Life Cycle Assessments of Municipal Solid Waste Management Systems - A Comparative Analysis of Selected Peer-Reviewed Literature. Environ. Int., 2009, 35, 12561266.

33. Denison, R. A. Environmental Life-Cycle Comparisons of Recycling, Landfilling and Incineration: A Review of Recent Studies. Annu. Rev. Energy Environ. 1996, 21, 191-237.

34. Franklin Associates. The Role of Recycling in Integrated Solid Waste Management to the Year 2000. Stamford, CT, 1994; From Denison, R. A. Environmental Life-Cycle Comparisons of Recycling, Landfilling and Incineration: A Review of Recent Studies. Annu. Rev. Energy Environ. 1996, 21, 191-237.

35. Lou, X. F.; Nair, J. The impact of landfilling and composting on greenhouse gas emissions - A review. Bioresour. Technol. 2009, 100, 3792-3798.

36. Stein, V. B.; Hettiaratchi, J. P. A. Methane oxidation in three Alberta soils: Influence of soil parameters and methane flux rates. Environ. Technol. 2001, 22, 101-111.

37. Environment Canada. Landfill Gas - Brock West Gas-to-Energy Project, 2003. http://www.ec.gc.ca/nopp/lfg/en/issue5.cfm. Accessed Nov 6, 2009.

38. C40 Cities. C40 Cities - Best Practices - Waste: City of Toronto Organic Waste, 2009. http://www.c40cities.org/bestpractices/waste/toronto_organic.jsp, Accessed Nov 21, 2009. 
Cite as: Mohareb E.A., MacLean H.L., \& Kennedy C.A., 2011. Greenhouse Gas Emissions from Waste Management - Assessment of Quantification Methods. Journal of the Air and Waste Management Association, 61, 480-493.

39. Barlaz, M. A.; Chanton, J. P.; Green, R. B. Journal of the Air and Waste Management Association 2009, 59, 1399-1404

40. USEPA. Solid Waste Management and Greenhouse Gases - A Life-cycle Approach to Sources and Sinks. 2006, $3^{\text {rd }}$ Edition.

41. Barlaz, M. A. Carbon storage during biodegradation of municipal solid waste components in laboratory-scale landfills. Global Biogeochem. Cycles 1998, 12, 373-380.

42. Benson, C. H.; Barlaz, M. A.; Lane, D. T.; Rawe, J. M. Practice review of five bioreactor / recirculation landfills. Waste Manage. 2007, 27, 13-29.

43. Amlinger, F.; Peyr, S.; Cuhls Carsten, C. Green house gas emissions from composting and mechanical biological treatment. Waste Manage. Res. 2008, 26, 47-60

44. Government of Ontario. Ontario’s Coal Phase Out Plan - Newsroom, 2009. http://news.ontario.ca/mei/en/2009/09/ontarios-coal-phase-out-plan.html Accessed June 10, 2010.

45. Lombardi, L., Carnevale, E. \& Corti, A. Greenhouse effect reduction and energy recovery from waste landfill, Energy, 2006 31, (15), pp. 3208-3219.

46. Hobson, A.M., Frederickson, J. \& Dise, N.B. $\mathrm{CH}_{4}$ and $\mathrm{N}_{2} \mathrm{O}$ from mechanically turned windrow and vermicomposting systems following in-vessel pre-treatment, Waste Manage., 2005, 25(4), 345-352.

47. Andersen, J.K. Quantification of greenhouse gas emissions from windrow composting of garden waste, J. Environ. Qual., 2010, 39(2), 713-724.

48. Brown, S.; Kruger, C.; Subler, S. Greenhouse gas balance for composting operations. J. Environ. Qual., 2008, 37(4), 1396-1410.

\section{About the Authors}

Eugene Mohareb is a Ph.D. candidate, Heather MacLean is an Associate Professor \& Christopher Kennedy is a Professor in the Department of Civil Engineering at the University of Toronto. Eugene Mohareb may be contacted at eugene.mohareb@mail.utoronto.ca. 
Table 1: Waste disposal data applied to the IPCC 1996, 2006, FCM-PCP and/or USEPA WARM for 2005 Waste GHG emission quantification ${ }^{18,19,20,21,22}$

\begin{tabular}{l|l|l|l}
\hline Waste Disposal Method & Tonnage & $\begin{array}{l}\text { Tonnes } \\
\text { Per Capita }\end{array}$ & Comments \\
\hline $\begin{array}{l}\text { Waste Landfilled - } \\
\text { MC approaches }\end{array}$ & $1,154,981^{\mathrm{a}, \mathrm{b}, \mathrm{c}, \mathrm{d}}$ & 0.210 & \\
\hline Waste Composted & $188,700^{\mathrm{a}, \mathrm{d}}$ & 0.034 & \\
\hline Waste Incinerated & $91,000^{\mathrm{a}, \mathrm{d}}$ & 0.016 & \\
\hline Waste AD'd & $72,448^{\mathrm{d}}$ & 0.013 & ${ }^{\mathrm{a}}$ Allocated to "Waste Composted" \\
\hline Backyard Compost & $69,888^{\mathrm{d}}$ & 0.013 & ${ }^{\mathrm{d}}$ Assumed to be carbon neutral \\
\hline Recycled & 446,719 & 0.080 & \\
\hline
\end{tabular}

${ }^{\mathrm{a}}$ Applied to WARM Model, ${ }^{\mathrm{b}}$ Applied to FCM-PCP Model, ${ }^{\mathrm{c}}$ Applied to IPCC 1996, ${ }^{\mathrm{d}}$ Applied to IPCC 2006

Table 2: Parameters applied to the IPCC 1996, 2006 and/or USEPA WARM for 2005 Waste Emission GHG quantification

\begin{tabular}{l|l|l}
\hline Parameter & Value & Sources / Comments \\
\hline $\begin{array}{l}\text { Degradeable Organic Carbon } \\
\text { (DOC) fraction }\end{array}$ & $0.169^{\mathrm{b}}$, \\
$0.161^{\mathrm{c}}$ & $\begin{array}{l}\mathrm{b,c} \text { Using IPCC 1996, 2006 DOC defaults weighted based } \\
\text { on waste audits } \\
\text { default }{ }^{7,8}\end{array}$ \\
\hline DOC Carbon content based on IPCC
\end{tabular}


Table 3: Relevant parameters applied in calculating GHG emissions from waste collection ${ }^{3,7}$

\begin{tabular}{cccc}
\hline $\begin{array}{c}\text { Truck Capacity } \\
(\mathbf{t})\end{array}$ & $\begin{array}{c}\text { Fuel Economy } \\
(\mathbf{L} / \mathbf{1 0 0} \mathbf{~ k m})\end{array}$ & $\begin{array}{c}\text { Energy Density of Diesel } \\
(\mathbf{M J} / \mathbf{L})\end{array}$ & $\begin{array}{c}\text { Diesel Emissions Factor } \\
(\mathbf{t} / \mathbf{T J})\end{array}$ \\
\hline $34^{3}$ & $42^{3}$ & $35.8^{7}$ & $74.1^{7}$ \\
\hline
\end{tabular}

Table 4: Gross and Net 2005 Emissions from Waste Management Activities using IPCC 2006

Treatment Option Gross Emissions Per Tonne Disposed Emissions Offset Net Emissions

\begin{tabular}{lrrrr}
\hline & $\left(\mathbf{t ~} \mathbf{C O}_{2} \mathbf{e}\right)$ & $(\mathbf{t ~ C O} \mathbf{2} \mathbf{e}$ & \multicolumn{1}{c}{$\left(\mathbf{t ~ C O}_{2} \mathbf{e}\right)$} & \multicolumn{1}{c}{$\left(\mathbf{t ~} \mathbf{C O}_{\mathbf{2}} \mathbf{e}\right)$} \\
\hline Landfill (MC) & 348,300 & 0.302 & 57,000 & 291,000 \\
$\mathrm{AD}$ & 100 & 0.001 & 320 & -220 \\
Incineration & 29,800 & 0.327 & 9,200 & 20,600 \\
Composting & 75,100 & 0.398 & N/A & 75,100 \\
Transportation & 30,500 & N/A & N/A & 30,500 \\
\hline Total & 508,600 & & 67,600 & 441,100
\end{tabular}

Table 5: Sensitivity to Uncertain Values of 2005 GHG Emissions from Landfill

\begin{tabular}{ccccc}
\hline Parameter & Values & $\begin{array}{c}\text { IPCC 1996 } \\
\left(\mathbf{t C O}_{\mathbf{2}} \mathbf{e}\right)\end{array}$ & $\begin{array}{c}\text { IPCC 2006 } \\
(\mathbf{W I P}) \\
\left(\mathbf{t C O}_{\mathbf{2}} \mathbf{e}\right)\end{array}$ & $\begin{array}{c}\text { WARM } \\
(\mathbf{t C O}\end{array}$ \\
\hline LFG & 0.75 & 365,518 & 373,120 & $-52,841$ \\
Capture & 0.5 & 731,037 & 746,239 & 270,346 \\
& $\%$ Change & $100 \%$ & $100 \%$ & $612 \%$ \\
\hline \multirow{2}{*}{ Degradable } & 0.17 & 368,150 & 394,381 & N/A \\
Carbon & 0.21 & 454,774 & 487,177 & N/A \\
& $\%$ Change & $24 \%$ & $23 \%$ & N/A \\
\hline \multirow{3}{*}{ Oxidation } & 0.1 & 365,518 & 373,120 & N/A \\
& 0.2 & 324,905 & 331,662 & N/A \\
& $\%$ Change & $-11 \%$ & $-11 \%$ & N/A \\
\hline
\end{tabular}


Table 6: Estimates of 2005 Landfill GHG emissions for parameter estimates

\begin{tabular}{cccccccc}
\hline & $\begin{array}{c}\text { LFG } \\
\text { Capture }\end{array}$ & $\begin{array}{c}\text { Degradable } \\
\text { Carbon }\end{array}$ & $\begin{array}{c}\text { LFG } \\
\mathbf{C H}_{\mathbf{4}} \\
\text { Content }\end{array}$ & $\begin{array}{c}\text { Fraction } \\
\text { Dissimilated }\end{array}$ & Oxidation & $\begin{array}{c}\text { IPCC } \\
\mathbf{1 9 9 6} \\
\left.\mathbf{t C O}_{\mathbf{2}} \mathbf{e}\right)\end{array}$ & $\begin{array}{c}\text { IPCC 2006 } \\
(\mathbf{W I P}) \\
\left(\mathbf{t C O}_{\mathbf{2}} \mathbf{e}\right)\end{array}$ \\
\hline $\begin{array}{c}\text { Base } \\
\text { Case }\end{array}$ & 0.75 & $0.17 / 0.16$ & 0.5 & 0.5 & 0.1 & 365,500 & 373,100 \\
\hline $\begin{array}{c}\text { Low } \\
\text { Case }\end{array}$ & 0.75 & $0.17 / 0.16$ & 0.4 & 0.4 & 0.2 & 207,900 & 212,300 \\
\hline $\begin{array}{c}\text { High } \\
\text { Case }\end{array}$ & 0.5 & 0.21 & 0.5 & 0.5 & 0.1 & 909,500 & 974,400 \\
\hline
\end{tabular}

Table 7: Comparison of Features of Four Models for Quantifying GHGs from Landfills

\begin{tabular}{|c|c|c|c|c|}
\hline & PCP-FCM & $\begin{array}{l}\text { USEPA } \\
\text { WARM }\end{array}$ & IPCC 1996 & IPCC 2006 \\
\hline Stated Purpose & Inventorying & Planning & Inventorying & Inventorying \\
\hline Model Type & $\mathrm{MC}$ & $\mathrm{MC}$ & $\mathrm{MC}$ & WIP \\
\hline Scope & Direct Emissions & LC Emissions & Direct Emissions & Direct Emissions \\
\hline LFG Capture Efficiency & Fixed & Variable & Variable & Variable \\
\hline Waste DOC Composition & Fixed & Variable & Variable & Variable \\
\hline Carbon Sinks & Not Qua & Quantified & Quantifiable & Quantifiable \\
\hline Waste Data Required & 1 year & 1 year & 1 year & $10-50$ years \\
\hline
\end{tabular}




\section{FIGURES}

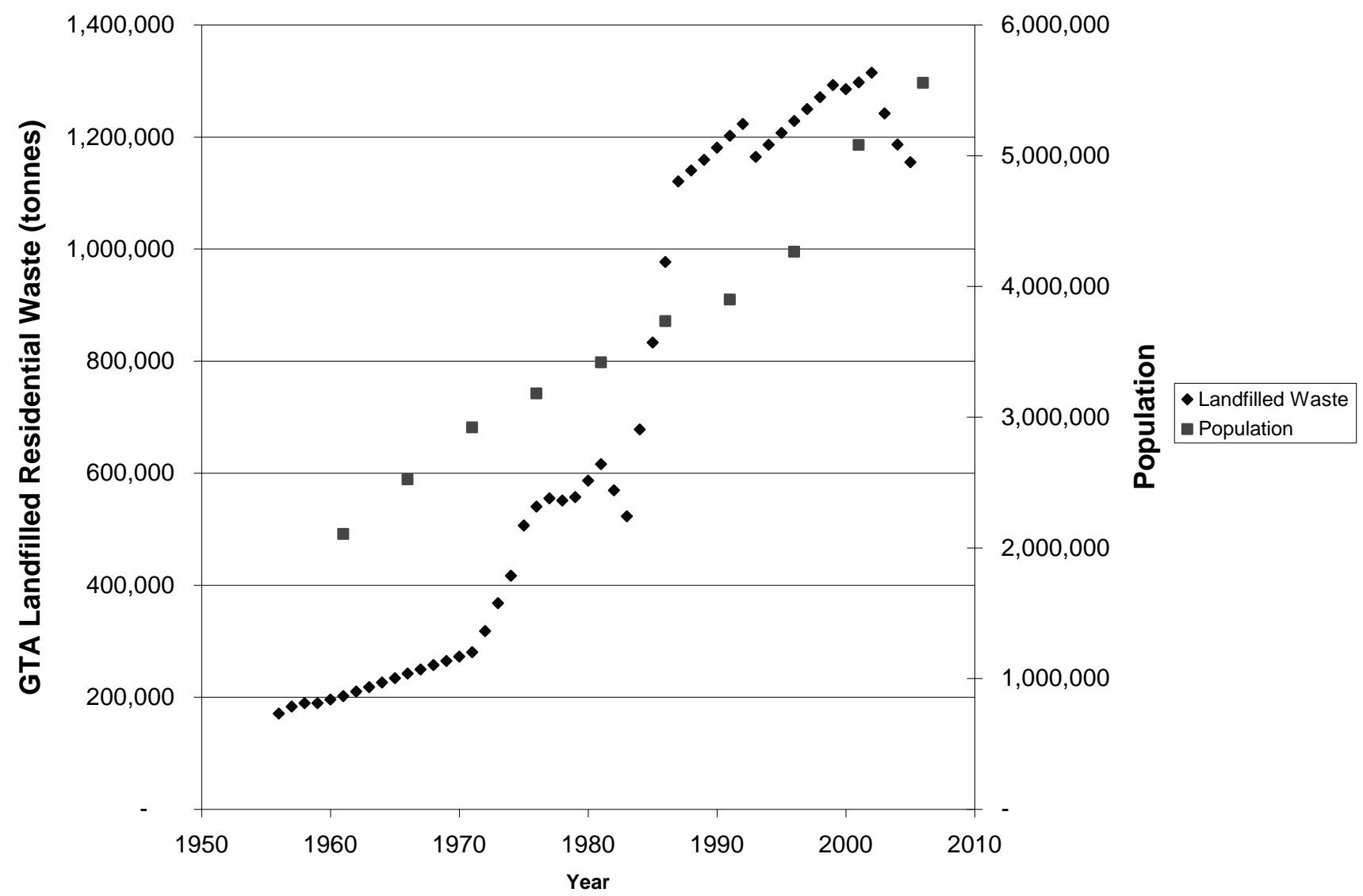

Figure 1: Waste disposed in landfills from the GTA between 1955-2005 


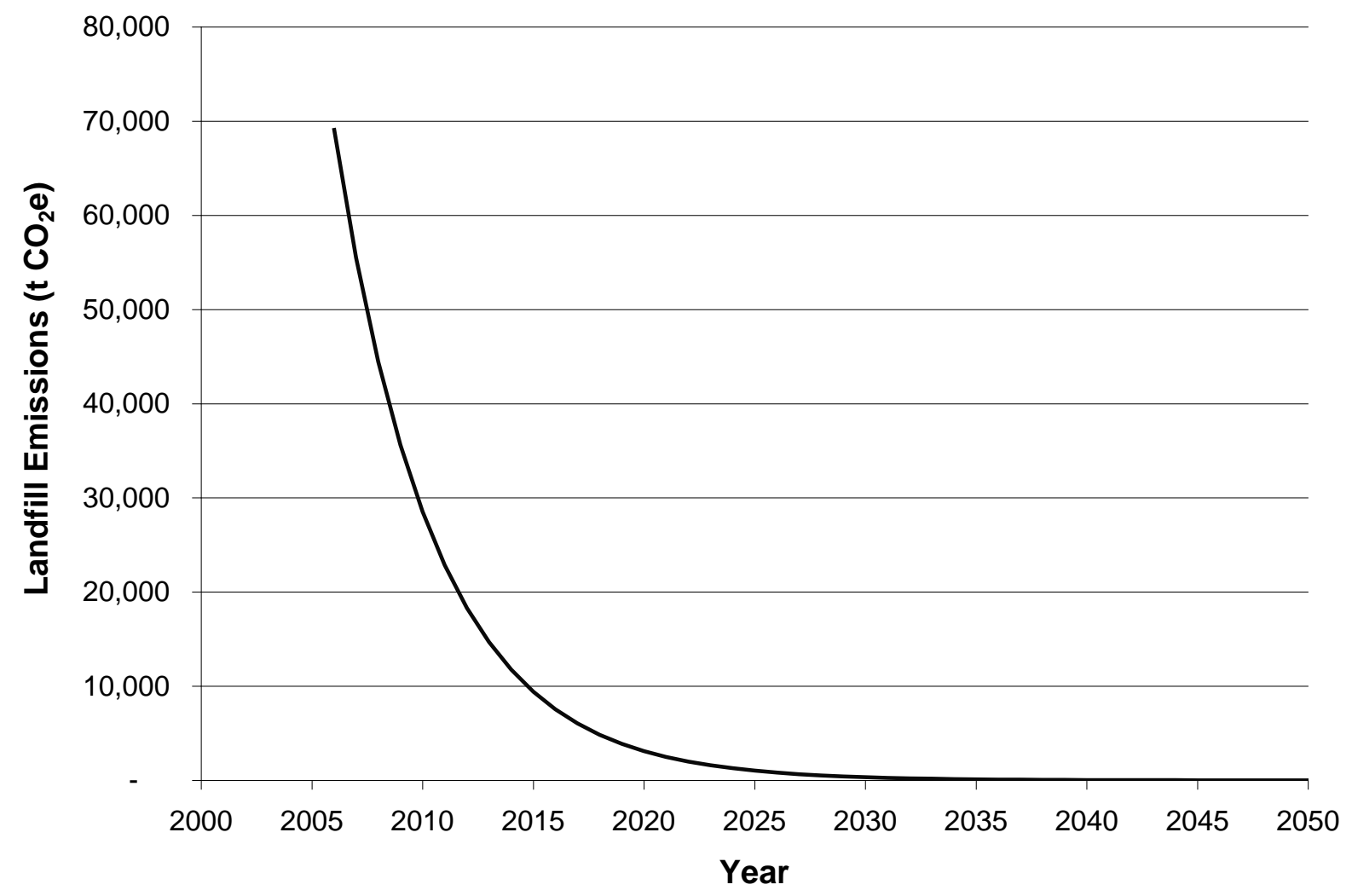

Figure 2: Plot of Methane Emissions from 2005 GTA Landfill Waste (IPCC 2006 MC)

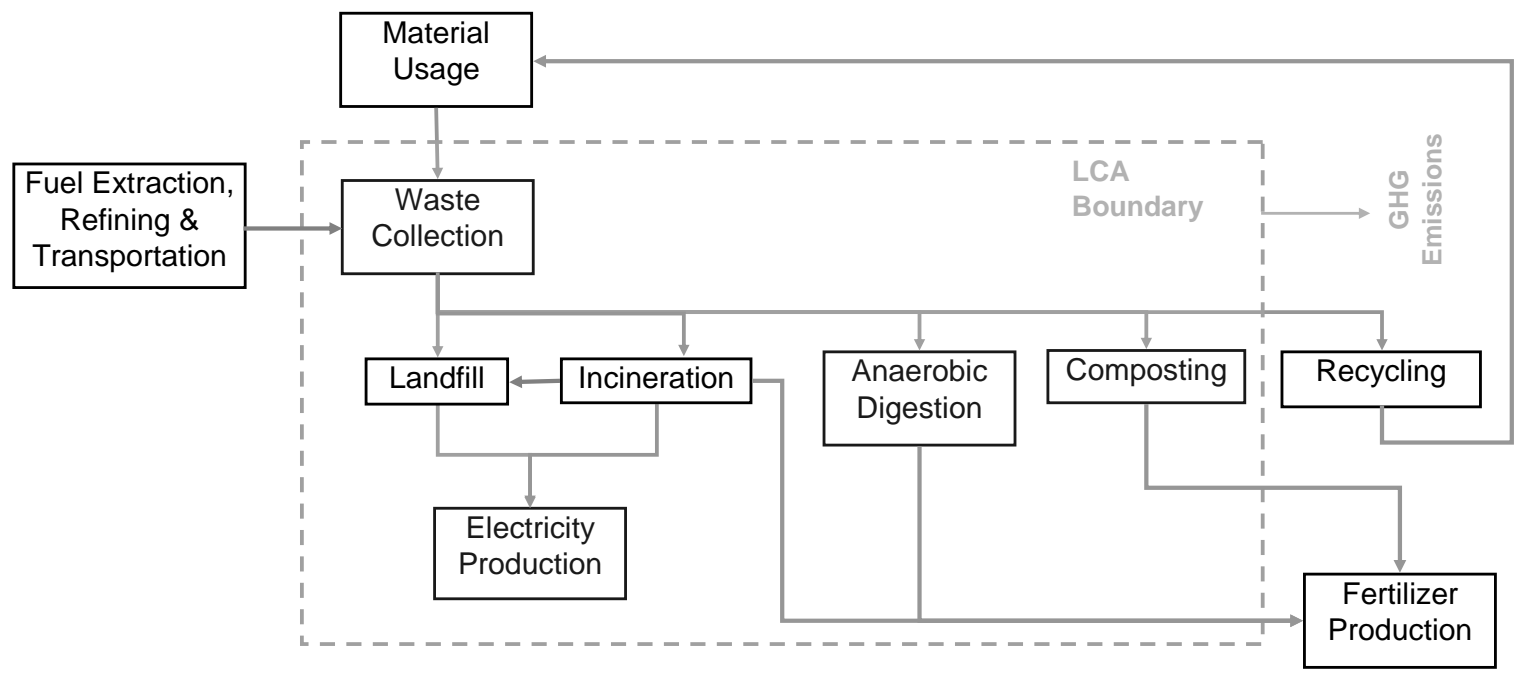

Figure 3: Flowchart displaying boundaries for conducted for IPCC 2006 LC 


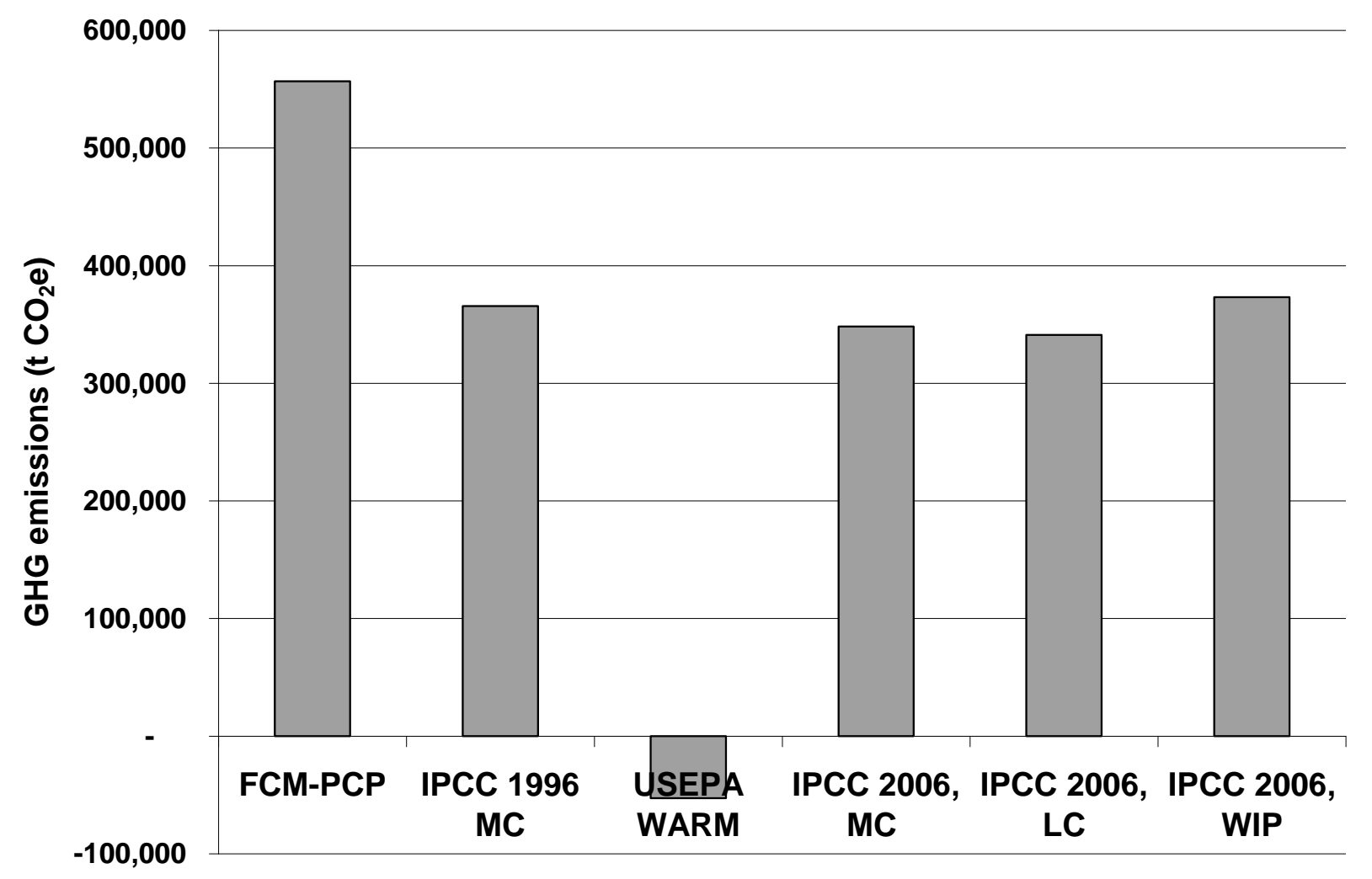

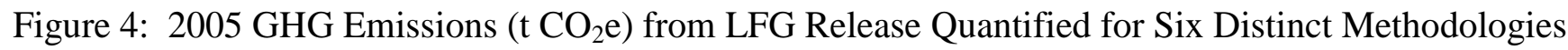




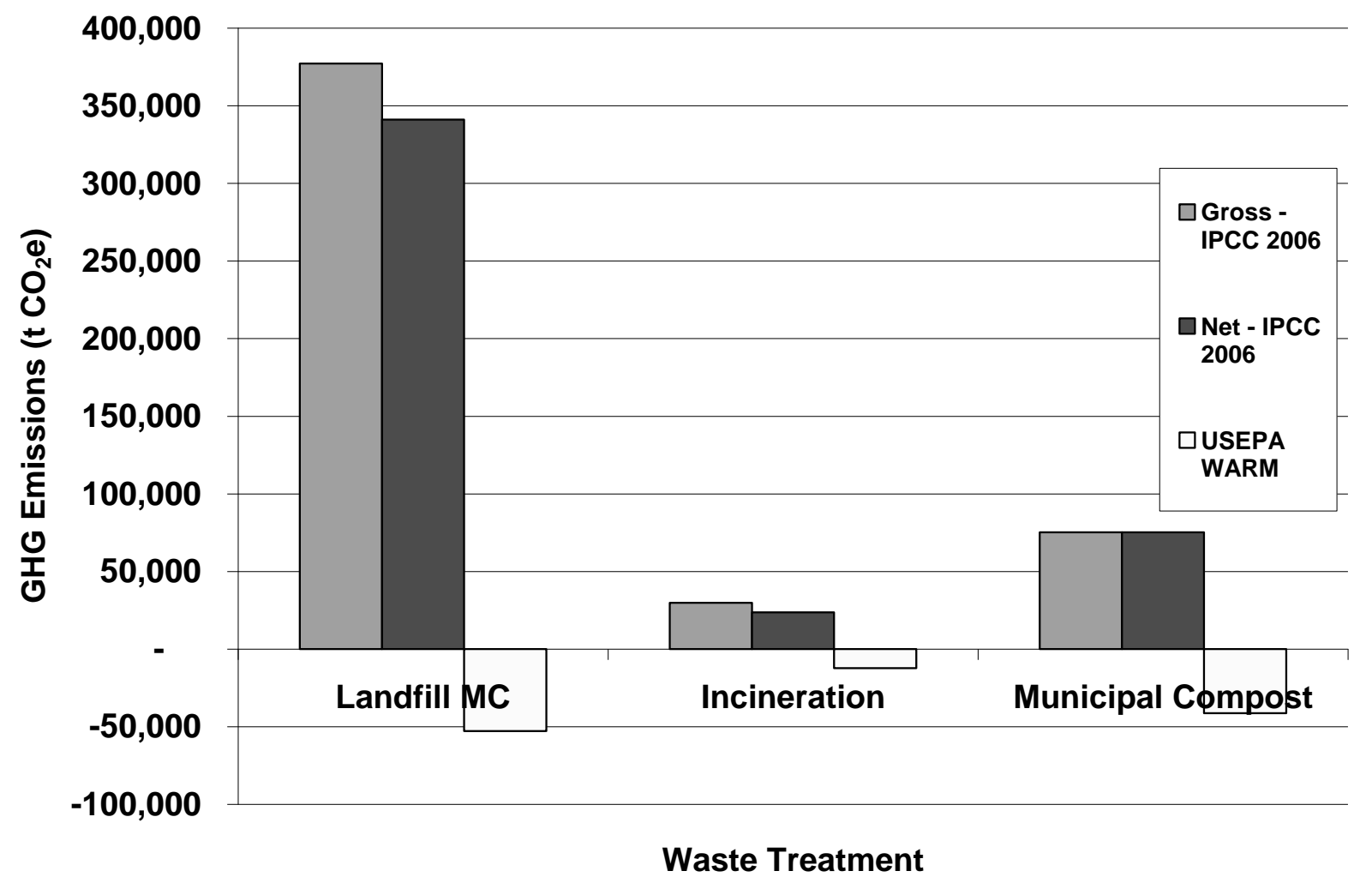

Figure 5: Gross \& Net 2005 GHG Emissions from Various Treatment Options for IPCC 2006, compared with USEPA WARM 
Cite as: Mohareb E.A., MacLean H.L., \& Kennedy C.A., 2011. Greenhouse Gas Emissions from Waste Management - Assessment of Quantification Methods. Journal of the Air and Waste Management Association, 61, 480-493. 